\title{
Aile Desteğinin Örgütsel Dışlanma ile İşten Ayrılma Niyeti İlişkisindeki Rolü ${ }^{1}$
}

\author{
DOI: 10.26466/opus.753300 \\ * \\ $\underline{\text { Kemal Köksal }}$ - Ali Gürsoy** - Yusuf Tuta *** \\ *Dr.Öğr. Üyesi, Akdeniz Üniversitesi \\ E-Posta: kemalkoksal@akdeniz.edu.tr \\ ORCID: $0000-0001-7653-1762$ \\ ** Dr., Kara Kuvvetleri Komutanlığı \\ E-Posta: agursoy75@gmail.com \\ ORCID: $\underline{0000-0002-8408-2415}$ \\ ***Öğr.Grv., Milli Savunma Üniversitesi \\ E-Posta: yusuftuta@hotmail.com \\ ORCID: 0000-0003-0643-2704
}

\section{Öz}

Bireylerin, çalışma arkadaşları velveya yöneticileri tarafından biçimsel ya da doğal yapıdan veya her ikisinden birden uzak tutulması örgütsel dışlanma olarak adlandırılmaktadır. Örgütlerinden dışlanan bireyler, bir gruba ait olma, değerli hissetme, kontrol sahibi olma ve yaşamı anlamlı kılma ihtiyaçların karşılayamamaktadır. Dışlanma örgütlerde oldukça yaygın olarak ortaya çıkmakta ve çalışan için acı verici olmakla birlikte, fiziksel, psikolojik ve örgütsel çeşitli olumsuz tutum ve davranışlara neden olmaktadır. Aile desteği bireyin ihtiyaç duyduğu ait olma ve kendini değerli hissetme gibi ihtiyaçların karşılamasına yardımcı olarak olumsuz tutum ve davranışları azaltabilmektedir. Çalışmada örgütsel dışlanmanın işten ayrılma niyeti üzerindeki etkisi ve bu etkide aile ve özel birisinin desteğinin düzenleyicilik etkisi araştırılmıştır. Araştırma kapsamında, Ankara ili Çankaya ilçesindeki yedi okulda görev yapan öğretmenlerden, kolayda örnekleme yöntemiyle 115 veri toplanmıştır. Toplanan veriler korelasyon ve regresyon analizi ile yorumlanmıştır. Araştırma sonucunda öğretmenlerin algıladıkları örgütsel dışlanmanın işten ayrılma niyetini artırdığı tespit edilmiştir. Alg̨lanan aile desteğinin yüksek olması işten ayrılma niyetini zayıflatmaktadır.

Anahtar Kelimeler: Örgütsel dışlanma, işten ayrılma niyeti, aile desteğgi, düzenleyici etki

\footnotetext{
${ }^{1}$ Bu çalışmanın bir önceki hali 01-02 Kasım 2019 tarihinde gerçekleştirilen VII. Örgütsel Davranış Kongresinde bildiri olarak sunulmuştur.
} 
ISSN: 2528-9527

E-ISSN : 2528-9535

Yıl Year: 11

Cilt Volume: 17

Sayı Issue: 35

Uluslararası Toplum Araştırmaları Dergisi

International Journal of Society Researches

Mart March 2021

Makalenin Gelis Tarihi Received Date. 15/06/2020

Makalenin Kabul Tarihi Accepted Date. 29/03/2021

\title{
The Role of The Family Support in The Relationship Between Workplace Ostracism and Intention to Quit
}

\begin{abstract}
Keeping the individuals away from a formal or informal structure or both by their colleagues and/or managers is called workplace ostracism. Individuals excluded from their organizations cannot meet the needs of belonging to a group, feeling valuable, controlling, and making life meaningful. Ostracism is quite common in organizations, and it is painful for the employee. It also causes various negative psychological and organizational consequences like developing negative attitudes and behaviors towards their organization. Family support can reduce these negative attitudes and behaviors by helping indi-viduals meet their needs, such as belonging and feeling valuable. This study explores the relationship between workplace ostracism and the intention to quit and the moderating effect of family support in this relationship. Within the research scope, 115 data were collected from the teachers working in seven schools in Çankaya district of Ankara province with a convenience sampling method. The collected data were analyzed by correlation and regression analysis. As a result, it was found that the workplace ostracism perceived by teachers increased the intention to quit and perceived family support weakened the intention to quit.
\end{abstract}

Keywords: Workplace ostracism, intention to quit, family support, moderating effect 


\section{Giriş}

Örgütler, bireylerin sadece örgüt amacını değil kendi amaçlarını da gerçekleştirmeye çalıştı̆̆ı, sosyal kimlik kazandığı ve sosyalleşme ihtiyaçlarını giderdiği yerlerdir (Katz, 1964). Örgütler oluşturulurken etkinlik ve verimlilik için rasyonel olarak yapılandırılır, çalışanları bu rasyonel yapıya uymaya zorlarlar ve çalışanlardan örgüt amaçlarına uygun davranmalarını beklerler. Ancak çalışanlar örgütlere, kendi kişiliklerini, beklentilerini ve becerilerini de taşıdıkları için çalışanlar arasında, örgütün biçimsel yapısından bağımsız, kendiliğinden gelişen doğal bir yapı da oluşmaktadır (Scott, 1992). Çalışma arkadaşları ve yöneticisi tarafından bazen biçimsel, bazen doğal yapıdan, bazen de her ikisinden de bazı çalışanlar uzak tutulabilmektedir. Dışlanma olarak isimlendirilen bu davranış (Williams, 2007) örgütlerde oldukça yaygın olarak karşılaşılmakta (Fox ve Stallworth, 2005; Hitlan, Kelly, Schepman, Schneider ve Zarate, 2006), çalışan için acı verici (Eisenberger ve Lieberman, 2004) olmakla birlikte, fiziksel, psikolojik ve örgütsel çeşitli olumsuz sonuçlara neden olmaktadır (Hitlan, Cliffton, ve DeSoto, 2006; Williams, 2007; Ferris, Brown, Berry, ve Lian, 2008). Örgütsel dışlanma, işyerinde gerçekleştirilen taciz, yıldırma ve istismar gibi kaba davranışlardan farklı bir yapıya sahiptir (Ferris, Chen ve Lim, 2017). Dışlanma, doğrudan çalışana yönelik az sayıda davranış içerse de çalışanların bir gruba ait olma, değerli olma, kontrol sahibi olma ve yaşamı anlamlı kılma ihtiyaçlarını tehdit etmesi nedeniyle bireyler açısından önem kazanmaktadır. (Williams, 2007).

Örgütler amaçlarına ulaşmak adına çalışanlar üzerinde belirleyici olabilmektedir. Çalışanlar yaşamlarının büyük bölümünün geçtiği örgütlerde, örgüt yaşamına ve onun kurallarına bağlı hayatlarını sürdürerek örgütsel kişilik ve kimlik kazanmaktadır. Örgütün ödül ve ceza sistemi, kariyer fırsatları ile örgütün biçimsel ve doğal yapısı nedeniyle çalışanlar örgütsel kişiliği benimsemektedir. Bürokratik örgütlerde, örgüt amaçlarını gerçekleştirmek için kurulan resmi, mesafeli ilişkiler ve örgütteki rekabet ortamı (ödüller, kariyer fırsatları, pozisyon vb.), çalışanların birbirlerine davranışını etkilemektedir (Loo, Der-Reijen ve Van, 2003). Örgütsel ve kişisel faktörlerden dolayı çalışan ve/veya yöneticiler kimi çalışanları izole edebilmektedir (Williams, 2007). 
Dışlanmanın örgütsel açıdan yıkıcı sonuçlarından bir tanesi de işten ayrılma niyetidir (Ferris, Brown, Berry ve Lian, 2008). Dışlanma nedeniyle örgütsel kimlik kazanamayarak örgütüne karşı yabancılaşan çalışan, işten ayrılmayı düşünebilmektedir. Ait olma duygusunu örgütünde kazanamayan çalışan, diğer bir kaynağa, başka bir ifade ile aile ve yakın çevresine yönelebilmektedir. Aile ve yakın çevresinden aldığı destek, işyerindeki stresin olumsuz etkilerini azaltabilmektedir (Lim, 1996).

Çalışmanın amacı, örgütsel dışlanmanın işten ayrılma niyeti üzerindeki etkisini ve bu etkide aile desteğinin düzenleyici rolünü incelemektir. Çalışmanın ulusal yazına üç açıdan katkısı olduğu değerlendirilmektedir. İlk olarak uluslararası yazında çalışanların fazlasıyla yaşadığı ifade edilen örgütsel dışlanmanın, ulusal düzeyde nasıl algılandığını göstermesi, ikinci olarak örgütsel dışlanmanın işten ayrılma niyetine olan olumsuz etkisini test etmesi ve son olarak aile desteğinin toplulukçu kültürde dışlanma ile işten ayrılma niyeti ilişkisindeki düzenleyici rolünü araştırmasıdır.

\section{Kavramsal Çerçeve}

\section{Örgütsel Dışlanma İşten Ayrnlma Niyeti İlişkisi}

Örgütsel dişlanma, bireylerin, işyerinde diğerleri tarafından yok sayılmasına veya göz ardı edilmesine yönelik algıları olarak tanımlanabilir (Ferris, Brown, Berry ve Lian, 2008). Farklı kültürlerde, farklı örgütlerde ve farklı pozisyonlarda yaygın bir şekilde karşılaşılan bir durumdur. Çalışanlara ihtiyaç duyduğu bilginin verilmemesi, sohbetlere alınmama, göz teması kurulmaması ve soğuk davranılması gibi örnekleri kapsamaktadır. Örgütsel dışlama bilinçli olabileceği gibi bilinçsizce de yapılabilmektedir ayrıca bir çalışan aynı olayı dışlanma olarak algılarken bir diğeri algılamayabilmektedir (Williams, 2007).

İşten ayrılma niyeti, çalışanın bilinçli olarak ve isteyerek işinden ayrılmayı düşünmesidir. Çalışanın işinden ayrılmasının önemli bir önceli olarak değerlendirilmektedir (Tett ve Meyer, 1993; Steel ve Ovalle, 1984). Çalışanlarl, işten ayrılmaya yönlendiren unsurların tespit edilmesi, örgütsel açıdan olumsuz sonuçları olan işten ayrılmaları önlemede önemlidir. İş yerinde diğerleri tarafından dışlanan çalışan, çalışma arkadaşlarına ve örgütüne karşı duyduğu sorumluluk ve bağl1lık hissinde azalma yaşayarak işinden ayrılmayı düşünmektedir (Hitlan, Kelly, Schepman, Schneider ve Zarate, 
2006). İşten ayrılma düşüncesi bireyin dışlanmadan kaynaklı yaşadığı psikolojik sıkıntıya karşı gösterdiği savunmacı bir tutumdur (Ferris, Brown, Berry ve Lian, 2008). Dışlanma nedeniyle kaybettiği ait olma, kendini değerli hissetme ve yaşamını anlamlı kılma gibi ihtiyaçlarını başka bir örgütte karşılama imkânını düşündürdüğü için işten ayrılma düşüncesi bireyi rahatlatıc da olabilmektedir (Maner, DeWall, Baumeister ve Schaller, 2007).

Yapılan çalışmalar örgütsel dişlanma ile işten ayrılma niyeti (Ferris, Brown, Berry ve Lian, 2008) arasındaki ilişkiyi göstermektedir (O'Reilly, Robinson, Berdahl ve Banki, 2015; Soybalı ve Pelit, 2018). Bu kapsamda araştırmanın bir numaralı hipotezi oluşturulmuştur.

- Hipotez 1: Örgütsel dışlanma işten ayrılma niyetini anlamlı ve pozitif olarak etkilemektedir.

\section{Aile Desteğinin Dïzenleyici Rolï}

Sosyal destek, bireyin stresini ve sağlığını etkileyen, takdir edilme, beğenilme, saygı görme gibi temel ihtiyaçlarına yönelik çalışma arkadaşları, yakın arkadaşları ve ailesiyle kurduğu iletişim olarak tanımlanabilir. Bireylerin sosyal desteğinin olması onların ruh sağlığı ve zorlu durumlarla mücadele etme gücünü olumlu bir şekilde etkilemektedir (Lakey ve Orehek, 2011). Sosyal destek kavramının farklı açılardan ele alınarak farklı şekilde çalışıdığı görülmektedir. Greenhaus ve Parasuraman (1994) sosyal desteği bireyin sahip olduğu ağın yapısı ve kaynakları olarak tanımlamıştır. Kaynaklar duygusal, bilgi, ekonomik ve dostluk gibi farklı şekillerde ve farklı amaçlara yönelik olabilmektedir. Desteğin algılanması ve gerçekleşmesi arasında da ayrım yapılabilir. Çalışmalar genelde bireyin sahip olduğu desteği nasıl algıladığı ve bu algısının çeşitli sonuçları nasıl etkilediğine yöneliktir. (Lakey ve Drew, 1997).

Algilanan sosyal desteğin nereden geldiğine göre farklı isimlerle kavramsallaştırıldığ 1 da görülmektedir. Bireyin çalıştığ örgütten aldığı destek, örgütsel destek olarak adlandırılmaktadır. Algılanan örgütsel destek, çalışanın örgütünün, bireye ne derece önem verdiği ve ne gibi katkıları olduğuna yönelikken, örgüt dışından, aile ve yakın çevresinden de bireye destek olabilmekte ve bu destek algılanan aile ve yakın çevre desteği (bundan sonra aile desteği diye kısaltılacaktır) olarak adlandırılmaktadır. Çalışmalar aile desteğinin bireyin genel yaşam tatminini artırdı̆̆ını fiziksel ve psikolojik 
stres ve endişesini azalttığını göstermektedir (Lim, 1996). Çalışan eğer aile desteğine sahipse, bu durum örgütsel dışlanmanın çalışanda yarattığı stresin olumsuz etkilerini zayıflatıcı olmaktadır (Fiset, Al Hajj ve Vongas, 2017). Birey, örgütte tatmin edemediği, gruba ait olma ve önemsenme ihtiyacını, ailede tatmin ederek stresini azaltabilmektedir (Baumeister ve Leary, 1995). Bu kapsamda araştırmanın iki numaralı hipotezi oluşturulmuştur.

Hipotez 2: Aile desteğinin yüksek olması, örgütsel dışlanmanın işten ayrılma niyeti üzerindeki etkisini zayıflatırken, düşük olması bu etkiyi artıracaktur.

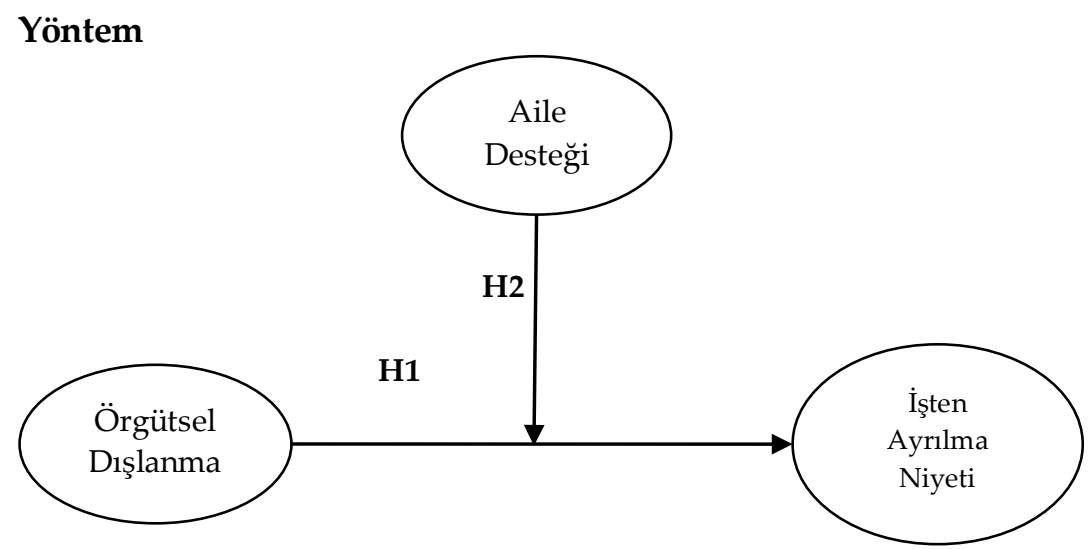

Şekil 1. Araştırma Modeli

Araştırmada çalışanın iş yerinde yaşadığı dışlanmanın işten ayrılma niyetini nasıl etkilediği ve aile desteğinin dışlanma ile işten ayrılma niyeti ilişkisinde düzenleyici etkisi olup olmadığı incelenmiştir. Araştırma kesitsel bir çalışma olup araştırmanın modeli Şekil 1'de gösterilmiştir.

\section{Örneklem ve Veri Toplama Yöntemi}

Çalışmanın evrenini Ankara ili, Çankaya ilçesinde bulunan özel okullarda çalışan öğretmenler oluşturmaktadır. Çalışmanın amacı değişkenler arasındaki ilişkiyi tespit etmek ve değişkenlerin birbirini yordama gücünü tespit etmek olduğu için, çalışma evreninden kolayda örneklem yöntemiyle, araştırmacıların ulaşılabildiği özel okul ve katılımcılardan veri toplanmıştır. Veriler 2018-2019 eğitim öğretim yılının bahar döneminde toplanmıştır. Özel okullarda, özellikle genç öğretmenlerde çalışan devir oranının yüksek 
olduğu ve diğer özel okullara geçişlerin hızlı bir şekilde yaşandığı değerlendirilmektedir. Örgüte yeni katılan bireylerin örgütle sosyalizasyonu sırasında kıdemli üyeler, yeni üyelere örgütteki işleyişi, kuralları, grup içinde nasıl davranılması gerektiğini öğretirler. Sosyalizasyon sürecinde bireyin sahip olduğu eski değerlerin yerine, yeni değerler kazandırılmaya çalışılır. Bu süreç her iki taraf için de sıkıcı olabilmekte ve uzun sürebilmektedir. Bu yüzden örgütün resmi sosyalizasyon sürecinin yanında, örgütte kendiliğinden oluşan doğal gruplara bireyin kabulü, sosyalizasyon sürecini hizlandırabilirken, doğal gruplara kabul edilmeme, diğer bir ifadeyle dışlanma bu süreci güçleştirebilmektedir (Robbins ve Judge, 2012). Ayrıca okullarda öğretmenler arasında yaşa, cinsiyete, inanca, siyasi görüşe, üye olunan sendikaya göre farklılıklar bulunmakta ve bu da dışlanmalara neden olabilmektedir (Erdemli ve Kurum, 2019).

Ülkemizdeki eğitim fakültesi mezunlarının sayısı ve özel okulların insan kaynakları politikaları subjektif olarak değerlendirilerek araştırma verilerinin özel okullardan toplanılmasına karar verilmiştir.

Verileri toplamak amaciyla Ankara Çankaya ilçesinde bulunan yedi özel okula 300 anket formu dağıtılmıştır. Çankaya ilçesinde Millî Eğitim Bakanlığına bağlı olarak faaliyet yürüten toplam 80 adet özel Fen ve Anadolu Lisesi bulunmaktadır. Bu liselerde görev yapan öğretmen sayısı 1743'tür. Araştırmanın yapıldığ liselerde çalışan öğretmen sayısı 2018-2019 eğitim öğretim yılında toplam 325'tir (Millî Eğitim Bakanlığı, 2020). Dağıtılan anketlerden 130 tanesi geri toplanabilmiştir. Geri dönüş oranı yaklaşık $\% 43$ tür. 130 anketin incelemesi sonucunda analize uygun olmayan anketlerin çıkarılması sonucunda 115 anket kalmıştır. Katılımclardan \%46,1'i $(n=53)$ kadın, \%53,9'u (n=62) erkektir. \%53,9'u evli (n=62), \%46,1'i (n=53) bekârdır. \%33'ü (n=38) 21-30 yaş, \%46,1'i (n=53) 31-40, \%17,4' ü (n=20) 41-50, $\% 3,5^{\prime} \mathrm{i}(\mathrm{n}=4) 51$ ve üstü yaş arasındadır. \%73,9'u ( $\left.\mathrm{n}=85\right)$ lisans mezunu, $\% 21,7^{\prime}$ si $(n=25)$ yüksek lisans ve $\% 4,3$ '̈ü $(n=5)$ doktora mezunudur.

\section{Ölçekler}

Araştırmada kullanılan ölçekler beşli Likert (1=Kesinlikle katılmıyorum, 5=Kesinlikle katıliyorum) olarak hazırlanmıştır.

Örgütsel Dışlanma Ölçeği: Çalışanların işyerinde yaşadıkları sosyal dışlanma algılarını ölçmek amacıyla Ferris ve arkadaşları (2008) tarafından 
geliştirilen ve Türkçe uyarlaması Çalışkan ve Pekkan (2019) tarafından yapılan ölçek kullanılmıştır. Ölçek 13 ifade ve tek boyuttan oluşmaktadır. Ölçekte "Diğer çalışanların çoğunlukla beni umursamadığını düşünüyorum.", "Diğer çalışanlar ben yokmuşum gibi davranır." gibi ifadeler bulunmaktadır. Ölçekten alınan yüksek puanlar örgütsel dışlanma algısının yüksek olduğunu göstermektedir.

İşten Ayrılma Niyeti Ölçeği: Çalışanların işten ayrılmaya yönelik niyetlerini ölçmek amacıyla Camman ve arkadaşları (1983) tarafından geliştirilen, Mimaroğlu (2008) tarafından Türkçeye uyarlanan üç ifadeli ve tek boyutlu ölçek kullanılmıştır. Ölçekte "Sık sık işi bırakmayı düşünüyorum." gibi ifadeler vardır. Yüksek puan işten ayrılma niyetinin yüksek olduğunu ifade etmektedir.

Sosyal Destek Ölçeği: Çalışanın ailesi ve özel birisinden aldığı sosyal desteği ölçmek amacıyla Zimmet ve arkadaşları (1988) tarafından geliştirilen, Eker ve Arkar (1995) tarafından uyarlaması yapılan çok boyutlu sosyal destek ölçeği kullanılmıştır. Ölçeğin aile, yakın birisi ve çalışma arkadaşları desteği boyutu olmak üzere üç boyutu ve toplam 12 ifadesi vardır. Çalışmanın amacına uygun olarak çalışanın örgüt dışından aldığı sosyal desteği ölçmek amaciyla, aile ve özel birisi desteği tek boyutlu olarak ölçülmüştür. Ölçekte "Ailem gerçekten bana yardımcı olmaya çalışır.", "Sevinçlerimi ve üzüntülerimi paylaşabileceğim özel birisi vardır." gibi sekiz ifade bulunmaktadır. Ölçekten alınan yüksek puanlar aile ve özel birisinin desteğinin yüksek olduğunu göstermektedir.

\section{Verilerin Analizi}

Verilerin analizi için ilk olarak uç değerler incelenerek veri setinden temizlenmiştir. Daha sonrasında ölçeklerin istenilen yapıyı ölçmede ne kadar başarılı olduklarını tespit etmek amacıyla ölçüm modelinin uyumu, bileşim ve ayrışım geçerlilikleri kontrol edilmiştir. Son olarak hipotez testi için korelasyon ve regresyon analizleri yapılmıştır. Analizleri yapmak için SPSS 23.0, AMOS 23.0 programları ve Hayes (2013) tarafından geliştirilen SPSS PROCESS makro yazılımı kullanılmıştır.

Ortak Yöntem Varyans Analizi: Kesitsel çalısma deseninde, ortak yöntem varyans problemi, çalışma bulgularının güvenilirliğini etkileyen en önemli 
problemlerden biridir. Hipotez testi yapılmadan önce böyle bir problemin olup olmadığı Harman'ın tek faktör yöntemiyle kontrol edilmiştir. Bu yöntemde ölçekteki tüm ifadeler tek bir faktörde toplanarak döngüsüz rotasyona sokulmuştur. Bunun sonucunda açıklanan toplam varyansın \%29 olduğu tespit edilmiştir. Bu oran \%50'nin altında olduğu için ortak yöntem varyans problemi olmadığ sakoff, 2003).

\section{Ölçüm Modelinin Geçerlilik ve Güvenilirliği}

Ölçekler önceki çalışmalarda kullanıldığı için bu çalışmada doğrulayıcı faktör analizi yapılarak ölçüm modellerinin uyum değerleri incelenerek yap1 geçerlilikleri kontrol edilmiştir. Doğrulayıcı faktör analizi sonuçlarına göre tüm ölçeklerin uyum değerlerinin kabul edilebilir sınırlar içinde olduğu değerlendirilmiştir (Tablo 1).

Tablo 1. Ölçeklerin Doğrulayıcı Faktör Analizleri

\begin{tabular}{llllllll}
\hline Ölçek & $\chi^{\mathbf{2}}$ & sd & $\chi 2 /$ sd & RMSEA & CFI & GFI & RMR \\
\hline Örgütsel Dişlanma & 113,920 & 65 & 1,753 & 0,081 & 0,941 & 0,864 & 0,050 \\
\hline İşten Ayrrlma Niyeti & 1,030 & 2 & 1,030 & 0,016 & 1,000 & 0,989 & 0,078 \\
\hline Aile Desteği & 36,500 & 20 & 1,825 & 0,085 & 0,967 & 0,925 & 0,059 \\
\hline
\end{tabular}

Ölçeklerin yapı geçerliliğini test etmek maksadıyla bileşim ve ayrışım geçerlilikleri de incelenmiştir. Ölçeklerin standardize faktör yükleri ve açlklanan ortalama varyans (AOV) oranları, ortak paylaşılan varyans (OPV) oranları ve bileşik güvenilirlik (BG) değerlerine bakılmıştır. Sonuçlar Tablo 2'de sunulmuştur. Değerler incelendiğinde üç ölçekteki tüm faktör yüklerinin istenilen değer olan 0,50'nin üzerinde olduğu çoğu değerin iyi olarak kabul edilen 0,70 'e yakın veya üzerinde olduğu görülmektedir. Faktör yüklerinin ortalama varyans açıklama güçlerinin de 0,50'den yüksek, bileşik güvenilirlik değerlerinin de iyi olduğu görülmektedir. Bu sonuçlara göre ölçeklerin bileşim geçerliliğinin olduğu değerlendirilmiştir. Ayrışım geçerliliği için ise OPV değerleri ile AOV değerleri karşılaştırılmıştır. Ölçekler arasindaki OPV değerleri 0,163 ve 0,024'tür. Bu değerler AOV değerlerinin altında olduğu için ölçeklerin farklı yapıları ölçtügü değerlendirilmiştir (Hair, Black, Babin ve Anderson, 2010) . 
Tablo 2. Ölçek Maddelerinin Faktör Yükleri, Açıklanan Ortalama Varyans ve Bileşik Güvenilirlik Değerleri

\begin{tabular}{|c|c|c|c|c|c|c|c|c|c|}
\hline \multirow[t]{2}{*}{ Md. } & \multicolumn{3}{|c|}{ Sosyal Dişlanma (SD) } & \multicolumn{3}{|c|}{ İşten Ayrılma Niyeti (İAN) } & \multicolumn{3}{|c|}{ Aile Desteği (AD) } \\
\hline & FY & AOV & BG & FY & $\mathrm{AOV}$ & BG & FY & $\mathrm{AOV}$ & BG \\
\hline SD1 & 0,70 & & & & & & & & \\
\hline SD2 & 0,79 & & & & & & & & \\
\hline SD3 & 0,83 & & & & & & & & \\
\hline SD4 & 0,76 & & & & & & & & \\
\hline SD5 & 0,68 & & & & & & & & \\
\hline SD6 & 0,62 & & & & & & & & \\
\hline SD7 & 0,66 & 0,51 & 0,93 & & & & & & \\
\hline SD8 & 0,76 & & & & & & & & \\
\hline SD9 & 0,76 & & & & & & & & \\
\hline SD10 & 0,76 & & & & & & & & \\
\hline SD11 & 0,59 & & & & & & & & \\
\hline SD12 & 0,65 & & & & & & & & \\
\hline SD13 & 0,65 & & & & & & & & \\
\hline İAN1 & & & & 0,78 & & & & & \\
\hline İAN2 & & & & 0,83 & 0,64 & 0,84 & & & \\
\hline İAN3 & & & & 0,79 & & & & & \\
\hline $\mathrm{AD} 1$ & & & & & & & 0,74 & & \\
\hline AD2 & & & & & & & 0,71 & & \\
\hline AD3 & & & & & & & 0,70 & & \\
\hline $\mathrm{AD} 4$ & & & & & & & 0,80 & 0.56 & 091 \\
\hline AD5 & & & & & & & 0,85 & 0,0 & \\
\hline AD6 & & & & & & & 0,72 & & \\
\hline AD7 & & & & & & & 0,71 & & \\
\hline AD8 & & & & & & & 0,74 & & \\
\hline
\end{tabular}

FY: Faktör Yükleri, AOV: Açıklanan Ortalama Varyans, BG: Bileşim Güvenilirliği

Ölçeklerin güvenilirliklerini kontrol etmek amaciyla Cronbach alfa değerlerine bakılmıştır. Dışlanma ölçeğinin Cronbach alfa değeri 0,93, işten ayrılma niyetinin 0,846 ve aile desteğinin 0,911 olarak tespit edilmiştir. Bu sonuçlara göre ölçekler geçerli ve güvenilirdir.

\section{Bulgular}

Hipotez testinden önce değişkenlerin ortalama, standart sapma ve korelasyon değerleri incelenmiştir. Sonuçlar Tablo 3'te sunulmuştur. Sonuçlara göre katılımcıların örgütsel dışlanma, işten ayrılma niyeti ve aile desteği alg1 ortalamalarının ortanca değerden (3) düşük olduğu görülmektedir. Örgütsel dışlanma ile işten ayrılma niyeti arasında pozitif yönlü ve anlamlı orta düzeyde bir ilişki söz konusudur. 
Tablo 3. Ortalama, Standart Sapma ve Korelasyon Değerleri

\begin{tabular}{lllll}
\hline Değişkenler & Ort. & S.S. & 1 & 2 \\
\hline 1-Örgütsel dişlanma & 1,72 & 0,53 & & \\
\hline 2-İssten ayrilma niyeti & 1,98 & 0,72 & $0,36^{* *}$ & \\
\hline 3-Aile desteği & 2,21 & 0,87 & $-0,14$ & 0,03 \\
\hline${ }^{* *} \mathrm{p}<0,01$ & & & &
\end{tabular}

Araştırmanın bir numaralı hipotezini test etmek için basit doğrusal regresyon analizi yapılmıştır. Analiz sonucunda (Tablo 4) örgütsel dışlanmanın işten ayrılma niyetini anlamlı ve pozitif bir şekilde etkilediği tespit edilmiştir $(\beta=0,583, \mathrm{~F}=16,780, \mathrm{p}<0,001)$. Örgütsel dışlanma işten ayrılma niyetindeki \%12,2'lik bir değişimi açıklama gücüne sahiptir. Bu sonuca göre Hipotez 1 kabul edilmiştir.

Tablo 4. Regresyon Analizi Sonuçlan

\begin{tabular}{lllll}
\hline & $\beta$ & S.H & t & $\mathrm{p}$ \\
\hline Bağımlı Değişken İAN & & & & \\
\hline Sabit & 2,994 & 0,257 & 11,651 & 0,000 \\
\hline Örgütsel Dışlanma & 0,538 & 0,142 & 4,096 & 0,000 \\
\hline & & $\mathrm{R} 2=0,122$ & $\mathrm{~F}=16,780$ & $\mathrm{p}=0,000$ \\
\hline
\end{tabular}

Hipotez 2'yi test etmek için PROCESS makro yazllımındaki Model 1 kullanılmıştır (Hayes, 2013). Programda ilk olarak çoklu doğrusallık probleminden kaçınmak için düzenleyici değişkenle bağımsız değişkeni merkezileştirme seçeneği işaretlenmiştir. Daha sonra düzenleyicilik analizi yapılmıştır. Sonuçlar Tablo 5'te sunulmuştur. Bağımsız değişken, düzenleyici değişken ve etkileşim değişkeni birlikte analize dâhil edildiğinde $r$ karedeki değişimin anlamlı olduğu görülmektedir $(\Delta R 2=0,03, \mathrm{~F}=4,97, \mathrm{p}=0,02)$. Bu sonuca göre düzenleyicilik etkisi vardır.

Tablo 5. Aile Desteğinin Düzenleyicilik Etkisi

\begin{tabular}{lllllll}
\hline & $\beta$ & $\mathrm{S} . \mathrm{H}$ & $\mathrm{t}$ & $\mathrm{p}$ & $\mathrm{ASGA}$ & ÜSGA \\
\cline { 2 - 7 } Bağımlı Değişken: IAN & & & & & & \\
\hline Sabit & 2,51 & 0,10 & 26,05 & 0,00 & 2,32 & 2,71 \\
\hline Aile desteği & 0,11 & 0,13 & 0,82 & 0,41 & $-0,16$ & 0,37 \\
\hline Dişlanma & 0,20 & 0,20 & 0,98 & 0,33 & $-0,20$ & 0,61 \\
\hline Dişlanma X Aile desteği & $-0,50$ & 0,22 & $-2,23$ & 0,03 & $-0,94$ & $-0,06$ \\
\hline & $\mathrm{R}^{2}=0,12$ & $\Delta \mathrm{R}^{2}=0,03$ & $\mathrm{~F}=3,42$ & $\mathrm{p}=0,02$ & & \\
\hline
\end{tabular}

ASGA: Alt sınır güven aralığı, ÜSGA: Üst sınır güven aralığı 
Düzenleyici etkinin yorumlanabilmesi amaciyla \pm bir standart sapma değerlere göre etki grafiği çizilmiştir (Şekil 2). Buna göre aile desteğinin yüksek olması örgütsel dışlanmanın işten ayrılma niyeti üzerindeki pozitif etkisini azaltmaktadır.

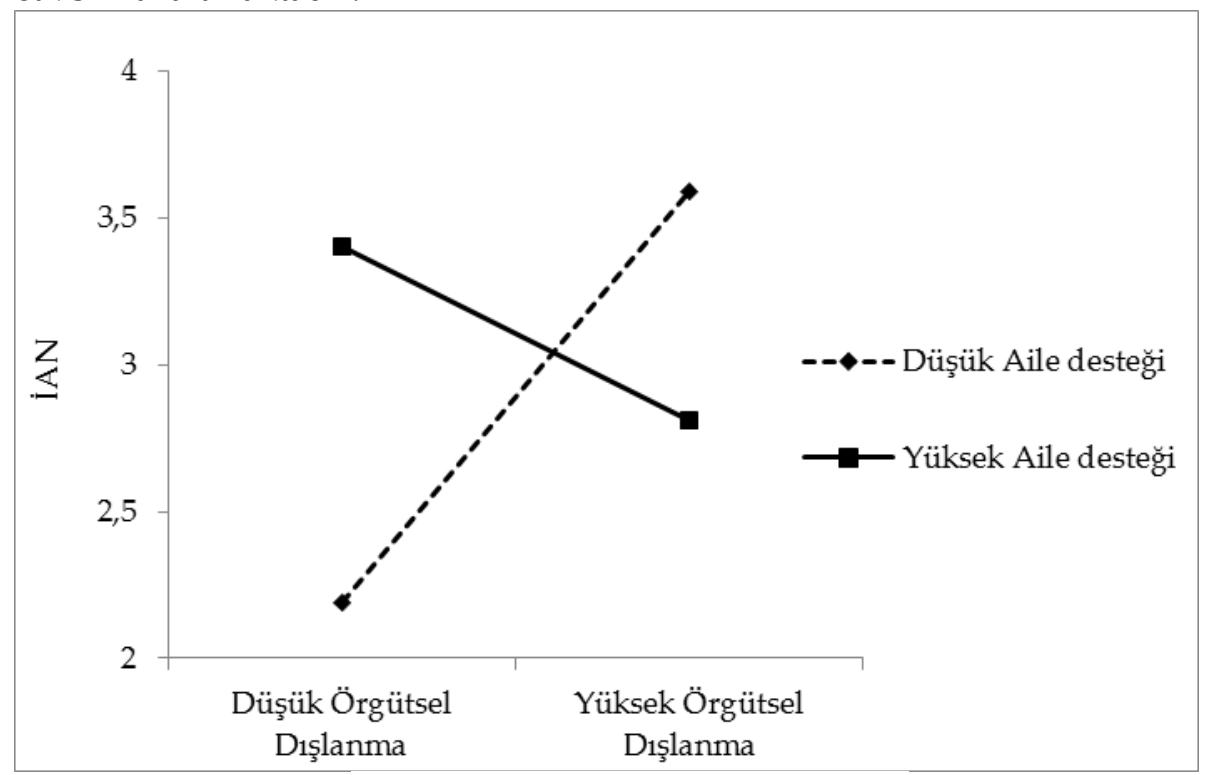

Şekil 2. Aile Desteğinin Düzenleyici Etkisi

\section{Sonuç ve Tartışma}

Araştırmada, çalışanların diğer arkadaşları ve yöneticisi tarafından görmezden gelinme, yalnız bırakılma ve çeşitli ortamlardan soyutlanma gibi örgütsel dışlanma algılamasının, işten ayrılma niyeti üzerindeki etkisi incelenmiştir.

Örneklemde yer alan katılımcıların genel olarak örgütsel dışlanma, işten ayrılma niyeti ve aile desteği algı ortalamalarının düşük olduğu sonucuna ulaşılmıştır.

Analiz sonucunda örgütsel dışlanmanın çalışanlarda işten ayrılma niyetini artırdığı görülmektedir. Örneklem kapsamındaki öğretmenler çalışma arkadaşları ve yöneticileri tarafından dışlandıklarını algıladıklarında işten ayrılmayı düşünmektedirler. Bu sonuç alan yazındaki diğer çalışma sonuçlarını doğrular niteliktedir. Polat ve Hiçyılmaz (2017) yaptıkları çalışmada okuldaki öğretmen ve yöneticilerin ayrımcı davranışlar gösterdiklerini ifade 
etmektedir. Öğretmenlerin yaşadıkları dışlanmanın sonucu; işe yabancılaşma düzeyleri artmakta (Abasll, 2018), örgütle olan uyumları azalmakta (Yılmaz, 2018), psikolojik sorunlar yaşanabilmekte, performanslarında, motivasyon ve aidiyetlerinde azalmalar olabilmektedir (Erdemli ve Kurum, 2019). Soybalı ve Pelit (2018) ise otel çalışanları üzerinde yaptıkları çalışmada örgütsel dışlanmanın işten ayrılma niyetini pozitif bir şekilde etkilediğini tespit etmişlerdir. Sonuç olarak örgütsel dişlanma öğretmenlerin işten ayrilma niyetlerini artırmaktadır.

Araştırmada, örneklemdeki öğretmenlerin algıladıkları aile desteğinin, örgütsel dışlanma ile işten ayrılma niyeti ilişkisinde düzenleyici etkisi de tespit edilmiştir. Bireyin sahip olduğu aile desteği, dışlanmanın işten ayrılma niyeti üzerindeki pozitif etkisini azaltmaktadır. Alan yazın incelendiğinde Halis ve Demirel (2016) yaptıkları çalışmada öğretmenlerin algıladıkları aile ve yakın arkadaş desteğinin dışlanmayı negatif ve anlamlı bir şekilde etkilediğini tespit etmişlerdir. Scot ve arkadaşları (2014) ile Fiset ve arkadaşları (2017) yaptıkları çalışmalarda dışlanmanın işten ayrılma niyetine olan etkisinde sosyal desteğin işten ayrılma niyetini artırdığını tespit etmişlerdir. Bu sonuç araştırma bulguları ile örtüşmemektedir. Hem Scott ve arkadaşları (2014) hem de Fiset ve arkadaşları (2017) sosyal desteği özellikle ekonomik destek olarak değerlendirmişler ve buna göre bireylerin işyerinde dışlanma yaşadıklarında işten ayrılma niyetinin arttığını, ekonomik ve sosyal ağ kapsamdaki sosyal desteğin işten ayrılma niyetini daha da şiddetlendirdiğini ifade etmektedir. Bu sonuç işyerinden dışlanan çalışanın, sosyal desteği sayesinde alternatif iş bulma ya da ekonomik destek sayesinde hayatını idame ettirme olanağına bağlanmaktadır.

Araştırma kapsamında ele alınan aile desteği daha çok manevi desteği içerdiğinden ve ülkemizdeki kültürel özelliklerden dolayı, aile desteği kişinin dişlanma nedeniyle iş yerinde tatmin edemediği ait olma, değerli hissetme ve kontrol gibi ihtiyaçlarını karşıladığı yer olmaktadır. Riskten kaçınan bir aile yapısında işten ayrılmaya teşvikten daha ziyade durumun gelecekte düzeleceğine yönelik umutlarla işe devam etme kararının tavsiye edildiği değerlendirilmektedir.

Çalışmada örgütsel dışlanma algısının öğretmenlerin işten ayrılma niyetini artırdığı tespit edilmiştir. İşten ayrılma niyeti işten ayrılmanın önemli bir önceli olduğundan (Steel ve Ovalle, 1984) yöneticiler açısından önem arz etmektedir. Örgüte çeşitli maliyetleri olan işten ayrılma davranışı gibi yıkı1ı 
örgütsel bir sonucu önlemek için, çalışanlar arasındaki farklılıkları azaltan, ortak noktaları vurgulayan bir örgüt kültürü yaratılarak dışlanmanın nedenleri ortadan kaldırılabilir.

Bundan sonra yapılacak çalışmalarda dışlanmanın işten ayrılma niyeti üzerindeki etkisinde, çalışanların sahip olduğu ekonomik desteğin ve sosyal sermayesinin düzenleyici rolü incelenebilir. Çalışmanın kesitsel bir çalışma olması ve kolayda örnekleme yöntemi ile veri toplanması sonucunda araştırma sonuçlarının genelleşememesi bu çalışmanın kısıtıdır. 


\title{
EXTENDED ABSTRACT
}

\section{The Role of The Family Support in The Relationship Between Workplace Ostracism and Intention to Quit}

\author{
Kemal Köksal - Ali Gürsoy - Yusuf Tuta \\ Akdeniz University, National Defense Ministry, National Defense University
}

Organizations are places where individuals try to realize their organizational goals and their own goals, gain social identity, and meet their socialization needs (Katz, 1964). Organizations are structured rationally for efficiency and productivity; they force employees to comply with this rational structure and expect employees to act according to its objectives. However, as employees carry their personalities, expectations, and skills to the organizations, an informal structure independent of their formal system also develops (Scott, 1992). Some employees are kept away from the formal, sometimes informal structure, sometimes both by their co-workers and managers. This behavior, called ostracism (Williams, 2007), is quite common in organizations (Fox and Stallworth, 2005; Hitlan, Kelly, Schepman, Schneider, and Zarate, 2006). Although it is painful for the employee (Eisenberger \& Lieberman, 2004), it also causes various negative psychological and organizational consequences (Hitlan, Cliffton, and DeSoto, 2006; Williams, 2007; Ferris, Brown, Berry, and Lian, 2008). Organizational ostracism has a different structure from rude behaviors such as harassment, mobbing, and abuse in the workplace (Ferris, Chen, and $\mathrm{Lim}, 2017)$. It gains importance for individuals because it threatens the need to make life meaningful. (Williams, 2007).

One of the organizationally destructive consequences of ostracism is the intention to quit (Ferris, Brown, Berry, and Lian, 2008). An employee alienated from his organization by not gaining an organizational identity due to ostracism may think of quitting his job. An employee who cannot achieve the feeling of belonging in his / her organization may turn to another source, in other words, his family and close circle. Support from family and intimate environment can reduce the adverse effects of stress in the workplace (Lim, 1996). 
The study aims to examine the effect of organizational ostracism on the intention to quit and the moderating role of family support in this effect. It is considered that the study contributed to the national literature in three ways. Firstly, it demonstrates how organizational ostracism, which workers experience in international literature, is perceived at the national level. Secondly, it tests the negative effect of organizational ostracism on the intention to quit and finally investigates the moderating role of family support in the relationship between ostracism and intention to quit in the collectivist culture.

The data were collected from seven private schools in the Çankaya region of Ankara province by convenience sampling method. Researchers considered that private schools' turnover rate and other private schools' transition, especially young teachers, is high.

During the socialization of new members of the organization, senior members teach the new members the organization's functioning, the rules, and how to behave in the group. In the socialization process, new values are tried to be gained instead of the individual's old values. This process can be boring for both parties and can take a long time. Therefore, in addition to the organization's official socialization process, the individual's acceptance of the informal groups can accelerate the socialization process. Not being accepted into informal groups, in other words, ostracism, can make this process difficult (Robbins and Judge, 2012). Also, there are differences among teachers in schools according to age, gender, belief, political view, and the union they are affiliated with, leading to ostracism (Erdemli and Kurum, 2019).

Before the hypothesis test, the mean, standard deviation, and correlation values were examined. According to the results, it is seen that the participants' perceptions of organizational exclusion, intention to quit, and family support are lower than the median (3). There is a positive and significant moderate relationship between organizational ostracism and intention to leave.

Results show that organizational ostracism increases the employees' intention to quit the job. When the teachers in the sample perceive that their colleagues and managers exclude them, they think of leaving their jobs. This result confirms the results of other studies in the literature. Polat and Hiçyılmaz (2017) stated in their research that teachers and administrators at school could display discriminatory behavior. As a result of the ostracism experienced by teachers, their level of alienation to job increases (Abasll, 2018), their alignment with the organization decreases (Y1lmaz, 2018), psychological 
problems may occur, and their job performance, motivation, and commitment may decrease (Erdemli and Kurum, 2019). Soybalı and Pelit (2018) found that organizational ostracism positively affected the intention to quit in their study on hotel employees. As a result, organizational ostracism increases teachers' intention to quit.

The study determined that the teachers' family support in the sample has a moderating effect on the relationship between organizational ostracism and the intention to quit. Family support of the individual reduces the positive impact of ostracism on the intention to quit. Halis and Demirel (2016) found in their study, teachers' perceptions of family and close friend assistance negatively and significantly affected ostracism. Scot et al. (2014) and Fiset et al. (2017) found that social support increased the intention to quit in the effect of ostracism on the intention to quit. This result is not consistent with the research findings. Both Scott et al. (2014) and Fiset et al. (2017) evaluated social support, especially economic support. Accordingly, they state that individuals' intention to quit increases when they experience ostracism in the workplace. Social support within the scope of economic and social networks further intensifies the intention to quit. This result is attributed to the employee's ability, who is excluded from the workplace, to find alternative employment thanks to social support or to survive through economic aid.

Since the family support discussed within the research scope includes more moral support, and because of the cultural characteristics in our country, family support is where the person cannot satisfy his / her needs such as belonging, feeling valued, and control in the workplace due to ostracism. In a risk-averse family, it is considered that the decision to continue working with the hope that the situation will improve in the future is recommended rather than an incentive to quit.

Since the intention to quit is an important priority to quit (Steel \& Ovalle, 1984), it is essential for managers. Managers can eliminate the reasons for ostracism by creating an organizational culture that reduces differences among employees and emphasizes common points to prevent a destructive organizational outcome such as turnover behavior with various costs.

In future studies, researchers may examine the moderating role of employees' economic support and social capital in the effect of ostracism on the intention to quit. This study has a limitation. It is a cross-sectional study, and 
that the research results cannot be generalized because of collecting data with the convenience sampling method.

\section{Kaynakça / References}

Abasl, K. (2018). Örgütsel dişlanma, işe yabancilaşma ve örgütsel sinizm ilişkisine yönelik öğretmen görüşleri. Ankara: Hacettepe Üniversitesi Eğitim Bilimleri Enstitüsü.

Baumeister, R. F. ve Leary, M. R. (1995). The need to belong: desire for interpersonal attachments as a fundamental human motivation. Psychol. Bull., 117, 497-529. doi:10.1037/0033-2909.117.3.497

Cammann, C., Fichman, M., Jenkins, D. ve Klesh, J. R. (1983). Assessing the attitudes and perceptions of organizational members. S. E. Seashore, E. E. Lawler, P. H. Mirvis, ve C. Cammann, Assessing Organizational Change: A Guide to Methods, Measures, and Practices içinde (s. 71-138). New York: John Wiley, Inc. .

Çalışkan, A. Ve Pekkan, N. Ü. (2019). Örgütsel dışlanma: Bir ölçek uyarlama çalışması, 7. Örgütsel Davranış Kongresi Bildiriler Kiltabı, Burdur.

Eisenberger, N. I. ve Lieberman, M. D. (2004). Why rejection hurts: A common neural alarm system for physical and social pain. Trends in Cognitive Science, 8, 294-300.

Eker, D. ve Arkar, H. (1995). Çokboyutlu Algılanan Sosyal Destek Ölçeği'nin faktör yapısı, geçerlik ve güvenirliği. Türk Psikoloji Dergisi, 34, 45-55.

Erdemli, Ö. ve Kurum, G. (2019). Okul yöneticisi ve öğretmenlerin gözünden okulda dışlanma: Nedenleri ve sonuçları. Hacettepe Üniversitesi Eğitim Fakültesi Dergisi., Advance online publication. doi:10.16986/HUJE.2019051589

Ferris, D. L., Brown, D. J., Berry, J. W. ve Lian, H. (2008). The development and validation of the workplace ostracism scale. Journal of Applied Psychology, 6, 1348-1366.

Ferris, D. L., Chen, M. ve Lim, S. (2017). Comparing and contrasting workplace ostracism and incivility. Annu. Rev. Organ. Psychol. Organ. Behav., 4, 315338.

Fiset, J., Al Hajj, R. ve Vongas, J. G. (2017). Workplace ostracism seen through the lens of power. Front. Psychol., 8(1528), 1-19. doi:10.3389/fpsyg.2017.01528

Fox, S. ve Stallworth, L. E. (2005). Racial/ethnic bullying: Exploring links between bullying and racism in the U.S. workplace. Journal Vocational Behavior, 66, 438-456. 
Greenhaus, J. H. ve Parasuraman, S. (1994). Work-family conflict, social support and wellbeing. M. J. Davidson, ve R. J. Burke, Women in Management: Current Research Issues içinde (s. 213-229). London: Paul Chapman.

Hair, J. F., Black, W. C., Babin, B. J. ve Anderson, R. E. (2010). Multivariate data analysis: a global perspective (7b.). New Jersey: Pearson Prentice Hall.

Halis, M. ve Demirel, Y. (2016). Sosyal desteğin örgütsel soyutlama (dışlanma) üzerine etkisi. Kastamonu Üniversitesi İktisadi ve İdari Bilimler Fakültesi Dergisi, 11, 318-335.

Hayes, A. (2013). An introduction to mediation, moderation, and conditional process analysis: A regression-based approach. New York: Guilford.

Hitlan, R. T., Cliffton, R. J. ve DeSoto, M. (2006). Perceived exclusion in the workplace: The moderating effects of gender on work-related attitudes and psychological health. North American J ournal of Psychology, 8, 217-236.

Hitlan, R. T., Kelly, K. M., Schepman, S., Schneider, K. T. ve Zarate, M. A. (2006). Language exclusion and the consequences of perceived ostracism in the workplace. Group Dynamics: Theory, Research, and Practice, 56-70.

Katz, D. (1964). The motivational basis of organizational behavior. Behavioral Science, 9(2), 131-146.

Lakey, B. ve Drew, J. B. (1997). A social-cognitive perspective on social support. G. R. Pierce, B. Lakey, G. Sarason, ve B. R. Sarason, Sourcebook of Social Support and Personality içinde (s. 107-140). New York, NY: Plenum.

Lakey, B. ve Orehek, E. (2011). Relational regulation theory: a new approach to explain the link between perceived support and mental health. Psychol. Rev., 118, 482-495. doi:10.1037/a0023477

Lim, V. K. (1996). Job insecurity and its outcomes: moderating effects of workbased and nonwork-based social support. Human Relations, 49, 171-194. doi:10.1177/001872679604900203

Loo, H., Der-Reijen, V. ve Van, W. (2003). Modernleşmenin paradoksları. İstanbul: İnsan Yayınları.

Maner, J. K., DeWall, C. N., Baumeister, R. F. ve Schaller, M. (2007). Does social exclusion motivate interpersonal reconnection? Resolving the porcupine problem. J. Pers. Soc. Psychol. , 92, 42-55. doi:10.1037/e633962013-015

Milli Eğitim Bakanlı̆̆ (2020). Millı Eğitim istatistikleri örgün eğitim. 28 Ocak 2020 tarihinde http://sgb.meb.gov.tr/www/icerikgoruntule.php? KNO=361 adresinden erişildi. 
Mimaroğlu, H. (2008). Psikolojik sözleşmenin personelin tutum ve davranışlarına etkileri: Tıbbi satış temsilcileri üzerinde bir araştırma: Satış temsilcileri üzerinde bir araştırma. Yayımlanmamış Doktora Tezi. Çukurova Üniversitesi Sosyal Bilimler Enstitüsü, Adana.

O'Reilly, J., Robinson, S. L., Berdahl, J. L. ve Banki, S. (2015). Is negative attention better than no attention? The comparative effects of ostracism and harassment at work. Organ. Sci., 26, 774-793. doi:10.1287/orsc.2014.0900

Podsakoff, P. M., MacKenzie, S. B., Lee, J. Y. ve Podsakoff, N. P. (2003). Common method biases in behavioral research: A critical review of the literature and recommended remedies. Journal of Applied Psychology, 88(5), 879-903.

Polat, S. ve Hiçyılmaz, G. (2017). Sınıf öğretmenlerinin maruz kaldıkları ayrımcılık davranışları ve bu davranışların nedenleri. Eğitimde Nitel Araştırmalar Dergisi, 5(2), 47-66. doi:10.14689/issn.2148-2624.1.5c2s3m

Robbins, S. P. ve Judge, T. A. (2012). Örgütsel davranış (14 b.). (E. İ. Erdem, Çev.) Ankara : Nobel Yayin.

Scott, K. L., Zagenczyk, T. J., Schippers, M., Purvis, R. L. ve Cruz, K. S. (2014). Coworker exclusion and employee outcomes: An investigation of the moderating roles of perceived organizational and social support. J.Manag. Stud. 51, 1235-1256. doi:10.1111/joms.12099

Scott, W. R. (1992). Organizations: Rational, natural, and open systems. Englewood Cliffs, NJ: Prentice-Hall.

Soybalı, H. H., ve Pelit, O. (2018). Örgütsel dışlanmanın işten ayrılma niyetine etkisi: Afyonkarahisar'daki beş yıldızlı otel işletmelerinde bir araştırma. Afyon Kocatepe Üniversitesi Sosyal Bilimler Dergisi, 20(3), 225-249.

Steel, R. P. ve Ovalle, N. K. (1984). A review and meta-analysis of research on the relationship between behavioral intentions and employee turnover. Journal of Applied Psychology, 69, 673-686. doi:10.1037/0021-9010.69.4.673

Tett, R. P. ve Meyer, J. P. (1993). Job satisfaction, organizational commitment, turnover intention, and turnover: path analysis based on meta-analytic findings. Personal Psychology, 46(2), 259.

Williams, K. D. (2007). Ostracism. Annual Rev. Psyc., 58, 425-452.

Yılmaz, Ö. (2018). İlkokul ve ortaokul öğretmenlerinin örgütsel dişlanma ve örgütsel uyum algilari arasindaki ilişki. Bolu : Bolu Üniversitesi Eğitim Bilimleri Enstitüsü.

Zimmet, G. D., Powel, S. S. ve K., F. G. (1988). The multidimensional scale of perceived social support. J. Pers Assess, 52, 30-41. 


\section{Kaynakça Bilgisi / Citation Information}

Köksal, K., Gürsoy A. ve Tuta, Y. (2021). Aile desteğinin örgütsel dışlanma ile işten ayrılma niyeti ilişkisindeki rolü. OPUSUluslararası Toplum Araştırmaları Dergisi, 17(35), 1925-1945. DOI: 10.26466/opus. 753300 